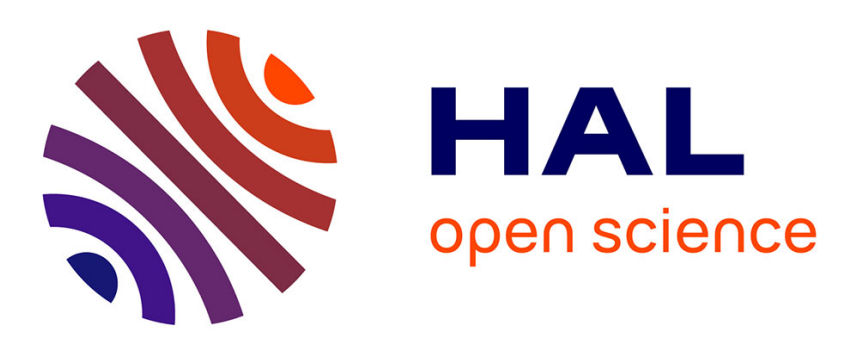

\title{
Variational Mode Decomposition-based Notch Filter for Bearing Fault Detection
}

Yassine Amirat, Elhoussin Elbouchikhi, Zhibin Zhou, Mohamed Benbouzid, Gilles Feld

\section{- To cite this version:}

Yassine Amirat, Elhoussin Elbouchikhi, Zhibin Zhou, Mohamed Benbouzid, Gilles Feld. Variational Mode Decomposition-based Notch Filter for Bearing Fault Detection. IECON 2019 - 45th Annual Conference of the IEEE Industrial Electronics Society, Oct 2019, Lisbon, Portugal. pp.6028-6033, 10.1109/IECON.2019.8926891 . hal-02972601

\section{HAL Id: hal-02972601 https://hal.science/hal-02972601}

Submitted on 28 Oct 2021

HAL is a multi-disciplinary open access archive for the deposit and dissemination of scientific research documents, whether they are published or not. The documents may come from teaching and research institutions in France or abroad, or from public or private research centers.
L'archive ouverte pluridisciplinaire HAL, est destinée au dépôt et à la diffusion de documents scientifiques de niveau recherche, publiés ou non, émanant des établissements d'enseignement et de recherche français ou étrangers, des laboratoires publics ou privés.

\section{(c)(1)}

Distributed under a Creative Commons Attribution| 4.0 International License 


\title{
Variational Mode Decomposition-based Notch Filter for Bearing Fault Detection
}

\author{
Yassine Amirat ${ }^{1}$, Elhoussin Elbouchikhi ${ }^{1}$, Zhibin Zhou ${ }^{1}$, Mohamed Benbouzid ${ }^{2,3}$ and Gilles Feld ${ }^{1}$ \\ 1 ISEN Brest, UMR CNRS 6024 IRDL, Brest, France \\ ${ }^{2}$ University of Brest, UMR CNRS 6024 IRDL, Brest, France \\ ${ }^{3}$ Shanghai Maritime University, Shanghai, China \\ Email: yassine.amirat@isen-ouest.yncrea.fr and elhoussin.elbouchikhi@isen-ouest.yncrea.fr \\ and zhibin.zhou@isen-ouest.yncrea.fr and mohamed.benbouzid@univ-brest.fr and gilles.feld@isen-ouest.yncrea.fr
}

\begin{abstract}
This work presents a variational mode decomposition (VMD) based detector for bearing fault in electrical machines. Its performance is compared to that of the ensemble empirical mode decomposition (EEMD) based. A notch filter based Pearson correlation was developed and used to extract the dominant mode. Experimental results showed that the VMD outperformed in terms of statistical features. As a result, the VMD-based notch filter could be a promising methodology for bearing fault detection and degradation prediction.

Keywords-induction motor, bearing fault, empirical mode decomposition, variational mode decomposition, intrinsic mode function rank.
\end{abstract}

\section{INTRODUCTION}

Electrical machines have became unavoidable device in industrial and domestic applications, for producing mechanical power or transforming it into electrical power. Despite electrical machines are robust devices, they remain subject to faults and downtime, hence, affecting their reliability performances. According to the defected component and the type of the electrical machine, faults can classified in three categories:

- Stator related fault: including electrical failures affecting the stator winding such as short-circuits, inter-turn short circuits and open-circuits [1].

- Rotor related fault: including electrical failures affecting the rotor winding, commutators/slip rings/brushes failures for all rotor wounded machines, and broken rotor bars and end-rings for squirrel-cage machines, and permanent magnet demagnetization or cracks for permanent magnet motors.

- Mechanical related fault: includes bearing failures, rotor eccentricity and shaft misalignment.

Figure 1 depicts the distribution of machines failures according the rate of the electrical machines [1]. Whatever the category of the faults, the safety and reliability of electrical machines are related directly to these faults, hence affecting the operation and maintenance cost. So, in order to be more reliable, condition monitoring systems with integrated fault detection algorithms must be implemented. For this purpose, many techniques and tools were developed in order to prevent failures and prolong their working life cycle as reviewed in [2]. Most of these techniques use the existing and pre-installed sensors for fault detection and monitoring, so, electric machine

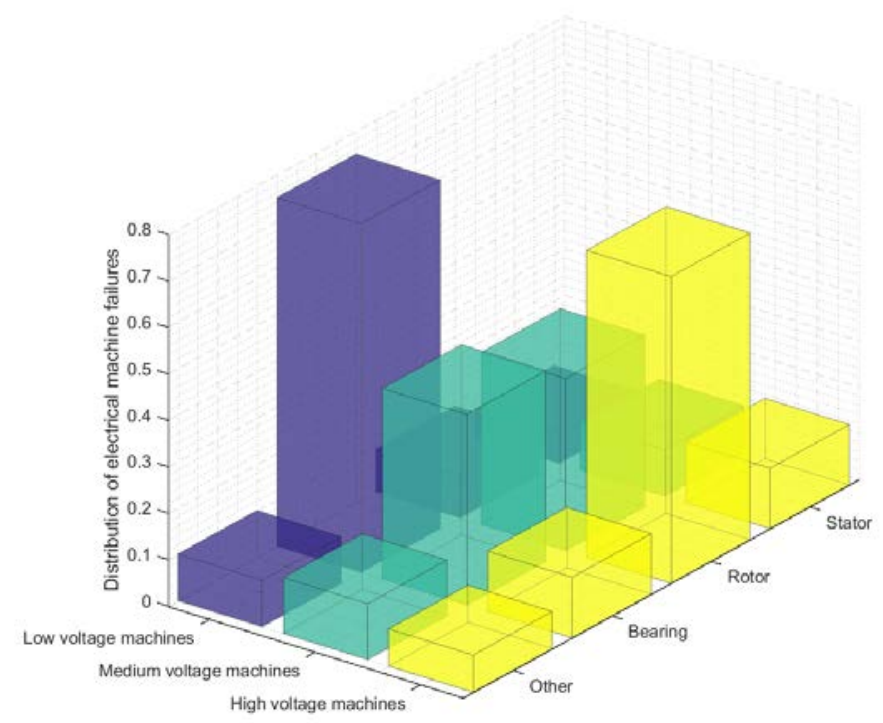

Fig. 1. Distribution of electrical machine failures depending on the voltage supply level [1].

quantities can be used as a fault transducer, and various survey papers [3]-[5], have indexed the well-established methods as: electrical quantities signature analysis (current, power...), vibration monitoring, temperature monitoring, and oil monitoring. However, the signature analysis of the electrical quantities is considered as a low cost technique, because there is no need to use additional sensors, since the electrical quantities are already used for control purpose and easily accessible during operation, i.e. the current can be acquired by current sensor, the voltage via a voltage sensor, and the power by computation [6]. Therefore, analysis of the machine electrical quantities needs the use of signal processing techniques. So, depending on the behavior of the electrical machine operation, specific signal techniques were investigated and developed, for example for steady-state operations, the most popular technique is the Fast Fourier Transform (FFT) and other techniques based on it [5], but for non stationary signals, FFT is difficult to interpret and it is difficult to extract features in time domain. To bridge the gap for non-stationary behavior, timefrequency and time-scale representations are investigated in 
electrical engineering community, Spectrogram and Quadratic Wigner-Ville are presented in [7], [8] for instance, and timescale analysis (wavelet) have been proposed in [9], however, these techniques have limitations such as high complexity poor resolution and presence of cross terms. Always in context of non stationary signals, parametric methods based on estimation of parameters of a known model are developed in [10], nevertheless, these methods have drawbacks they are formulated through integral transforms and analytic signal representations [11], hence they depend on data length and the accuracy of the model. To overcome the accuracy of the model dependency in a non stationary context, a data driven approach based on the Empirical Mode Decomposition (EMD) is introduced by [12], and The merits of the EMD were highlighted in various diagnostic and fault detection literature and applications. However this approach presents also some limitations and drawbacks, such as:

- The lack of mathematical theory

- The mixed mode presence

- The sensitivity to noise and sampling

- The result of decomposition is highly dependent on the sifting process and stopping criterion

So, to alleviate the mixed mode and sensitivity to noise and sampling problems, the Ensemble Empirical Mode Decomposition (EEMD) was introduced, and this technique has demonstrate its performances to detect fault [2]. However, both EMD and EEMD or other techniques based on them still suffer from the lack of theoretical background, for this purpose an other approach based on the variational mode decomposition (VMD) algorithm, and this paper attempts to assess the performances of EEMD and VMD for bearing fault detection. The study was carried out using experimental data from $0.75 \mathrm{~kW}$ test bench.

This paper is organized as follows. Section II highlights the EEMD and VMD algorithms, and focuses on signal decomposition into intrinsic mode function and variational mode, section III describes the notch filter based on measurement of the statistical distance between the original signal and the dominant mode, since section IV presents the statistical criterion for fault detection. Section V presents the obtained results and analyzes the performances of the EEMD and VMD algorithms.

\section{SignAL PRE-PROCESSING}

In various electrical applications, the ideal case is to get a pure sine wave electrical current with only the supply fundamental component, however, due to various phenomena such as eccentricity, slot, saturation,... the electric current contains more than the supply fundamental component, but also additional harmonics [13], and eventually a component introduced by the bearing failure.So, in order to detect the component introduced by the bearing failure in the electrical current, it is proposed to investigate an emerging signal processing algorithm known as the EEMD and the VMD. The EEMD is an empirically based data analysis method, since the
VMD is also data driven approach but with a mathematical theories.

\section{A. Ensemble empirical mode decomposition principle}

The EEMD is introduced by [12] to improve the EMD algortihm [14], and has become a tool for the analysis of nonstationary and nonlinear data [15] in a wide range application in signal processing [16] and fault detection [6], [17], [18]. The EEMD algorithm is depicted in 2 and its implementation is described step by step in [2] So, through EEMD algorithm,

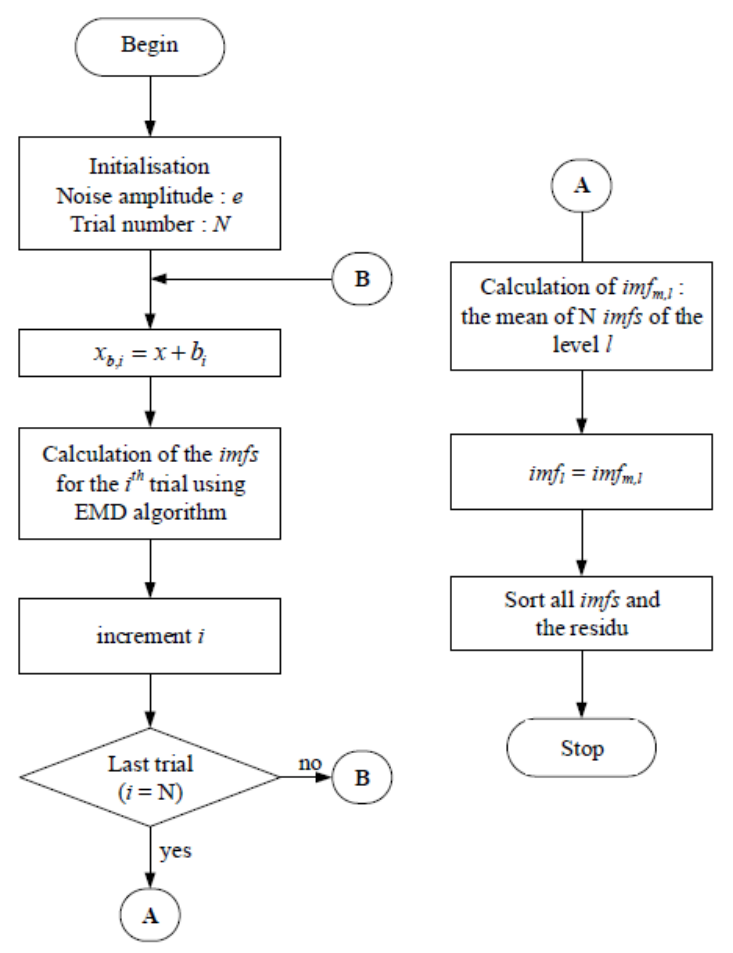

Fig. 2. EEMD algorithms for signal decomposition.

a signal $x(t)$ can be expressed as a sum of $k$ modes or $I M F S$ as follow

$$
x(t)=\sum_{i=1}^{k} I M F_{i}(t)+r e s(t)
$$

\section{B. Variational mode decomposition principle}

The VMD is an emerging signal processing algorithm. It has been proposed by [19] to answer the lack of theoretical background of the EMD algorithm. It has the ability to analyze non-stationary and nonlinear data, and was investigated in various fields such as in crude oil risk forecasting [20] and bearing fault detection [21], [22] [23]. The VMD is considered as a self-adaptive and quasi-orthogonal and entirely nonrecursive signal processing method, unlike the EMD/EEMD wich are self-adaptive but recursive methods. The core of the VMD algorithm is based on classical Wiener filtering, Hilbert transform, and heterodyne demodulation. Like the EEMD, a 
signal $x(t)$ can be decomposed by VMD algorithm into a $k$ modes or sub-signals $u_{k}(n)$, and each mode is compact around a center pulsation $\omega_{k}(t)$ [21], and $\mathrm{x}(\mathrm{n})$ can also be expressed by ?? as follows:

$$
x(t)=\sum_{i=1}^{k} \operatorname{Mode}_{i}(t)+\operatorname{res}(t),
$$

In addition, for VMD algorithm a constrained variational problem has to minimize the sum of each Mode component's bandwidth.

Consequently, the mathematical model of constrained variational problem can be given as follows [19] [24]:

$$
\min _{\left\{u_{k}\right\},\left\{\omega_{k}\right\}}\left\{\sum_{k=1}^{K}\left\|\partial_{t}\left\{\left[\delta(t)+\frac{\mathrm{j}}{\pi t}\right] * u_{k}(t)\right\} \mathrm{e}^{-\mathrm{j} \omega_{k} t}\right\|_{2}^{2}\right\}
$$

s.t. $\sum_{k}\left\{u_{k}(t)\right\}=x(t)$,

where $u_{k}=\left\{u_{1}, u_{2}, \ldots, u_{k}\right\}$ represents the modal function vector, $\omega_{k}=\left\{\omega_{1}, \omega_{2}, \ldots, \omega_{k}\right\}$ is the central frequency vector.To resolve the constrained problem it must be transformed into an unconstrained problem, for this purpose a quadratic penalty factor $\eta$ and Lagrangian multiplier $\lambda(t)$ are introduced in [19], hence a new unconstrained variational problem expression is obtained as follows:

$$
\begin{aligned}
\Gamma\left(u_{k}, \omega_{k}, \lambda\right)= & \eta \sum_{k=1}\left\|\partial_{t}\left\{\left[\delta(t)+\frac{\mathrm{j}}{\pi t}\right] * u_{k}(t)\right\} \mathrm{e}^{-\mathrm{j} \omega_{k} t}\right\|_{2}^{2} \\
& +\left\|x(t)-\sum u_{k}(t)\right\|_{2}^{2} \\
& +\left\langle\lambda(t), x(t)-\sum u_{k}(t)\right\rangle
\end{aligned}
$$

Then to resolving this unconstrained problem we investigate the algorithm developed in [19], where its straightforward implementation is described step by step in 1 .

\section{NOTCH FILTER BY DISTANCE MEASUREMENT}

As mentioned in previous subsections, the decomposition of signal $x(t)$ through EEMD and VMD leads to a sum of modes or sub-signals as expressed in 1 and 2 respectively, among these modes, at least one mode is closely representative to the original signal, this mode is the dominant mode denoted Mode $_{d}(n)$. Assuming that the occurrence of a fault introduces a new component in the original signal, hence a specific mode or sub-signal denoted Mode $e_{e}$ is introduced in the mode decomposition of this original signal. Therefore the sampled signal $x(n)(n=1, \cdots, N)$ can be decomposed through both algorithms as follows:

$$
x(n)=\operatorname{Mode}_{d}(n)+\sum_{i=1}^{k<j} \operatorname{Mode}_{i}(n)+\operatorname{res}(n),
$$

The aim of the notch filter is to extract $\operatorname{Mode}_{d}(n)$, for this we propose to use a statistical tool based on the measurement of the distance between each $\operatorname{Mode}_{k}(n)$ and the original signal $x(n)$.

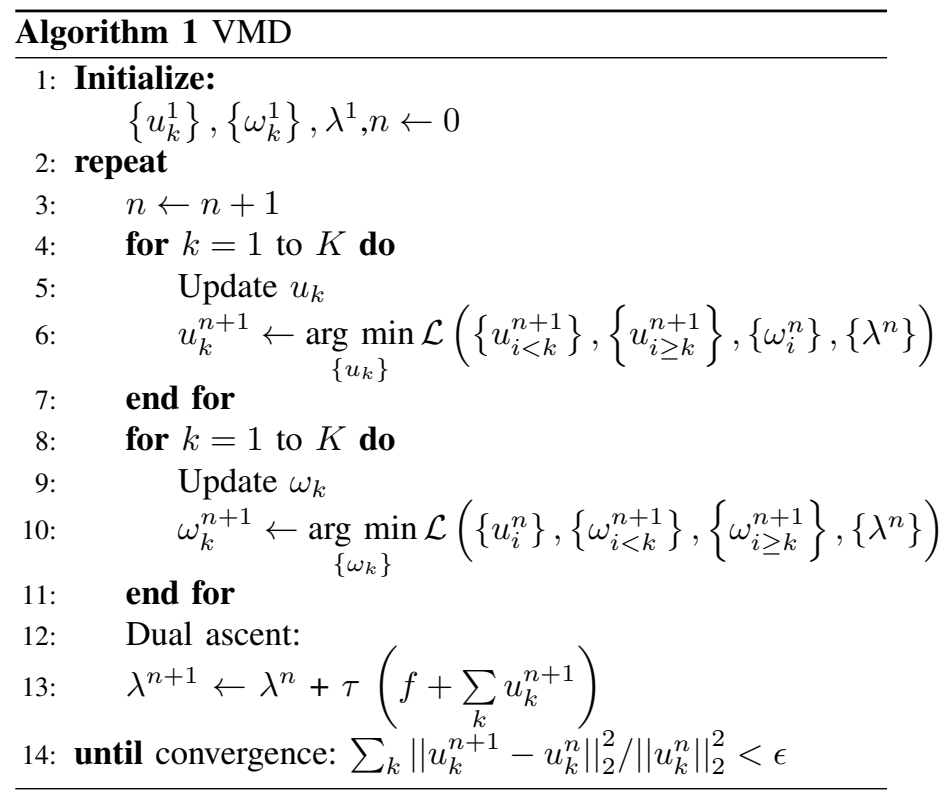

\section{A. Statistical distance measurement}

In statistic and information theories, a statistical distance quantifies the distance between two statistical quantities, which can be two random variables, or two probability distributions or samples. In statistics literature various approaches have been indexed and investigated in various fields, particularly for fault detection and diagnostic [25], [2]. The statistical tool knowen as Person correlation is used to measure the distance, and to give a weight to dependency between two two temporal series $x(n)$ and $y(n)$ [26]. This dependency is weighted by a coefficient denoted $r(x, y)$ and defined by 6 , a value of this coefficient close to -1 or 1 , indicates that $x(n)$ and $y(n)$ are highly correlated positively or negatively, respectively, while a value around 0 indicates that there is no dependency between $x(n)$ and $y(n)$.

$$
r(x, y)=\frac{\sum_{n}\left[\left(x(n)-m_{x}\right) *\left(y(n)-m_{y}\right)\right]}{\sqrt{\sum_{n}\left(x(n)-m_{x}\right)^{2}} \cdot \sqrt{\sum_{n}\left(y(n)-m_{y}\right)^{2}}}
$$

where $m_{x}$ and $m_{y}$ are the means of $x$ and $y$, respectively.

\section{B. Dominant Mode filtering}

The cancellation of the dominant Mode (i.e. IMf) is is illustrated in Fig. 3. The cancellation of the dominant Mode algorithm can be implemented in three steps:

- Step 1: The VMD (i.e. EEMD) is applied to calculate the set of modes (i.e. IMfs) contained in the analyzed signal,

- Step 2: Pearson Correlation coefficient is calculated using 6 as many times as there are modes, and then $r_{c} \approx 1$ indexes the Mode $_{d}$,

- Step 3: Then, the indexed Mode ${ }_{d}$ is subtracted from the analyzed signal $x(n)$ and the result denoted $x(n)_{c}$ and expressed by 7 , can therefore be used to detect bearing 
(Step 1)
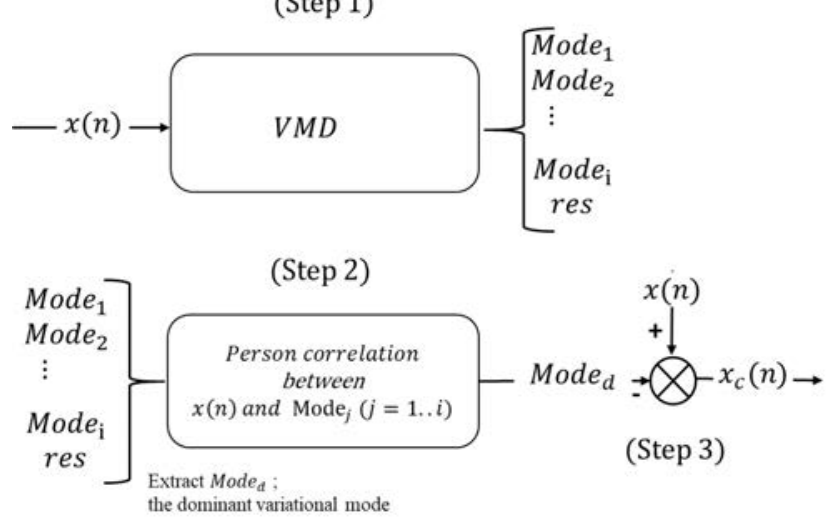

Fig. 3. Dominant Mode Cancellation [2].

failure .

$$
x_{c}(n)=x(n)-\operatorname{Mode}^{\cdot} \mathrm{d}_{c}(n)
$$

\section{FAult Detector}

For fault detection, several detectors based on statistics features are proposed in literature, in this work we investigate the statistical feature of the resultant signal $x_{c}$ obtained after dominant Mode subtraction. This statistical feature is the variance denoted $\sigma^{2}$ expressed by 8 , the advantage of such fault detector is its needless of training sequence [27]

The variance denoted $\sigma^{2}$ is expressed by [27]:

$$
\sigma^{2}=\frac{1}{N} \sum_{n=0}^{N-1}\left(\left|x_{c}(n)\right|-\mu\right)^{2}
$$

where $\mu_{k}$ is the average of $\left|x_{c}(n)\right|$, i.e.

$$
\mu=\frac{1}{(N)} \sum_{n=1}^{N}\left|x_{i}(n)\right|
$$

Therefore, the test to detect a fault is based on the following hypothesis:

- If $\sigma^{2}<\gamma$, the machine is healthy;

- If $\sigma^{2}>\gamma$, the machine is faulty.

where $\gamma$ is a threshold which can be set subjectively.

\section{Assessment of THE EEMD AND VMD BASED NOTCH FILTER}

For assessment purposes, a $0.75 \mathrm{~kW}$ induction motor is used. The experimental setup details can be found in [2]. In this context, Figs. 4, 5, 6, 7 displays the set of modes obtained after variational mode decomposition of the analyzed signal $x(n)$ for healthy case, cage defect case, ball defect case and inner race defect case, respectively.

Figures 8 and 9 illustrate Pearson correlation coefficients for both algorithms EEMD and VMD. This shows that both algorithms are able to extract the dominant dominant mode (i.e. IMF), but not at the same rank, for EEMD the $5^{\text {th }} \mathrm{imf}$

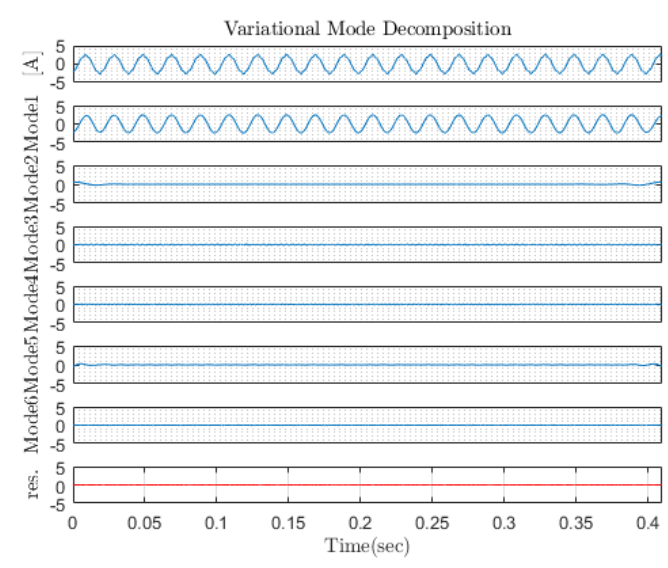

Fig. 4. Healthy VMD.

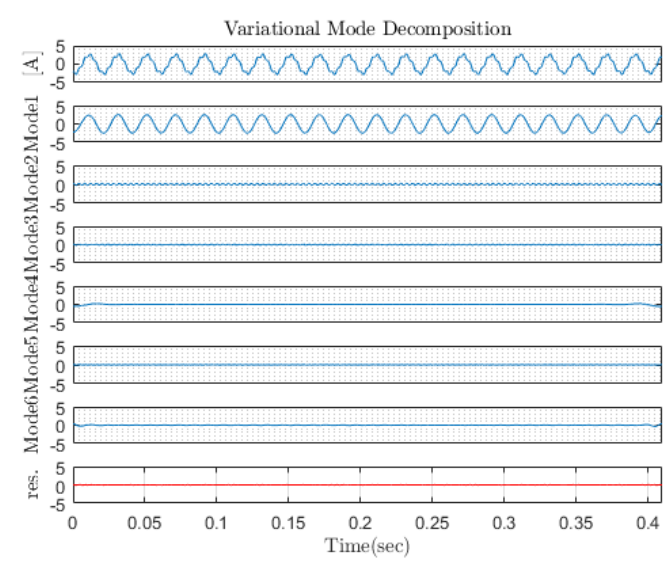

Fig. 5. Cage defect case VMD.

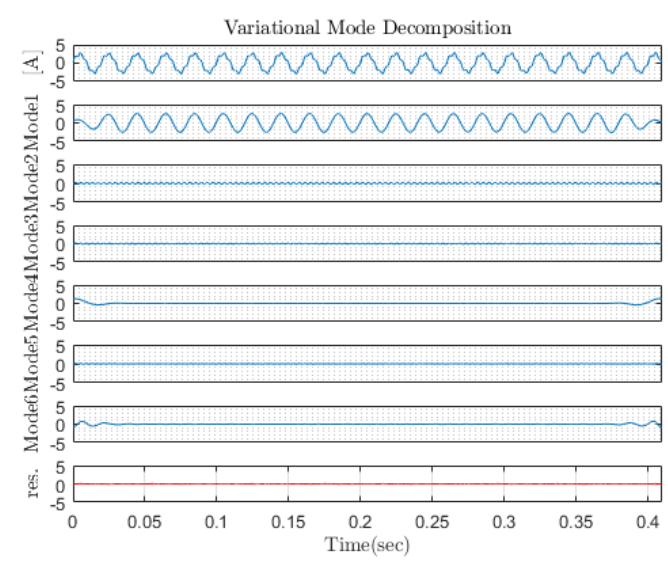

Fig. 6. Ball defect case VMD.

is the dominant mode while for the VMD it is the $1^{\text {st }}$ one. After the dominant mode subtraction, the fault detector $\sigma^{2}$ is evaluated for different cases, and the results are depicted in figure 10. It will be noted that $\sigma^{2}$ is not null even in healthy machine case for both algorithms. However, it can be noticed that $\sigma^{2}$ for faulty case is greater than one under healthy 


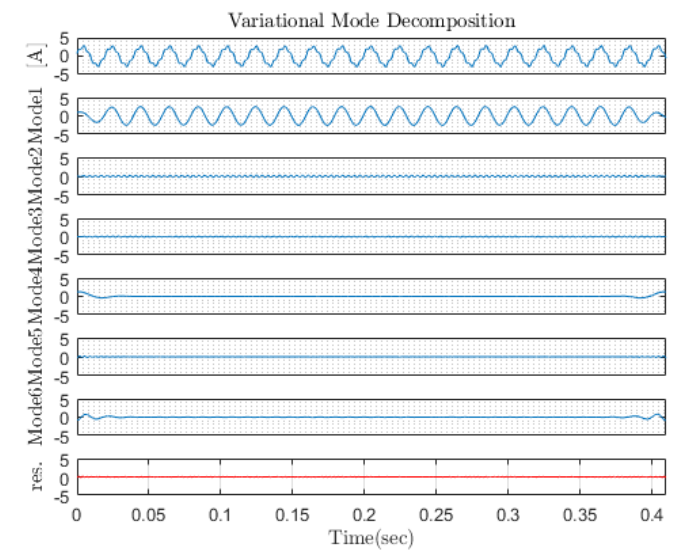

Fig. 7. Inner race defect case VMD.
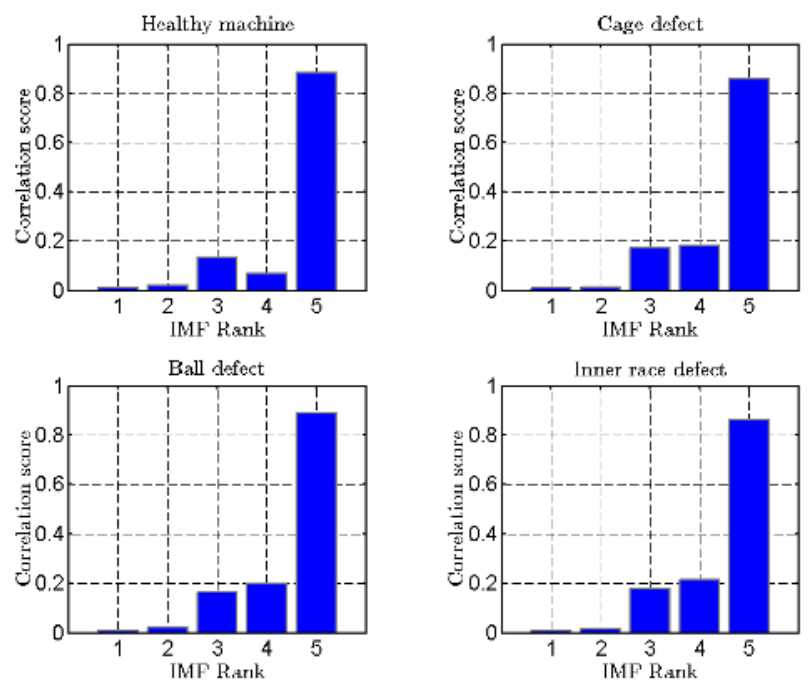

Fig. 8. Pearson correlation coefficients for EEMD.

condition. Under faulty condition, $\sigma^{2}$ is 5 times higher than $\sigma^{2}$ for $\sigma^{2}$ he healthy case for EEMD algorithm and is multiplied by 65 for VMD algorithm. The ratio $\sigma^{2}{ }_{f} / \sigma_{h}^{2}$ is reported in table Ifor both algorithms and for each fault.

\section{CONCLUSION}

Variational mode decomposition-based notch filter for bearing fault detection has been proposed and compared to EEMDbased notch filter. The filtering operation was carried out following three steps: the first step concerns the decomposition of the phase machine current into variational mode functions using the VMD algorithm, then et the second step the dominant mode is subtracted from the original signal, and finally in the last step a statistical feature is used as a fault

TABLE I

RATIO OF $\sigma^{2}$ FOR FAULTY CASE TO $\sigma^{2}$ FOR HEALTHY CASE.

\begin{tabular}{|c|c|c|c|}
\hline Algorithm & Cage defect & Ball defect & Inner race defect \\
\hline EEMD & 5.131 & 4.997 & 4.676 \\
\hline VMD & 65.492 & 66.740 & 64.415 \\
\hline
\end{tabular}

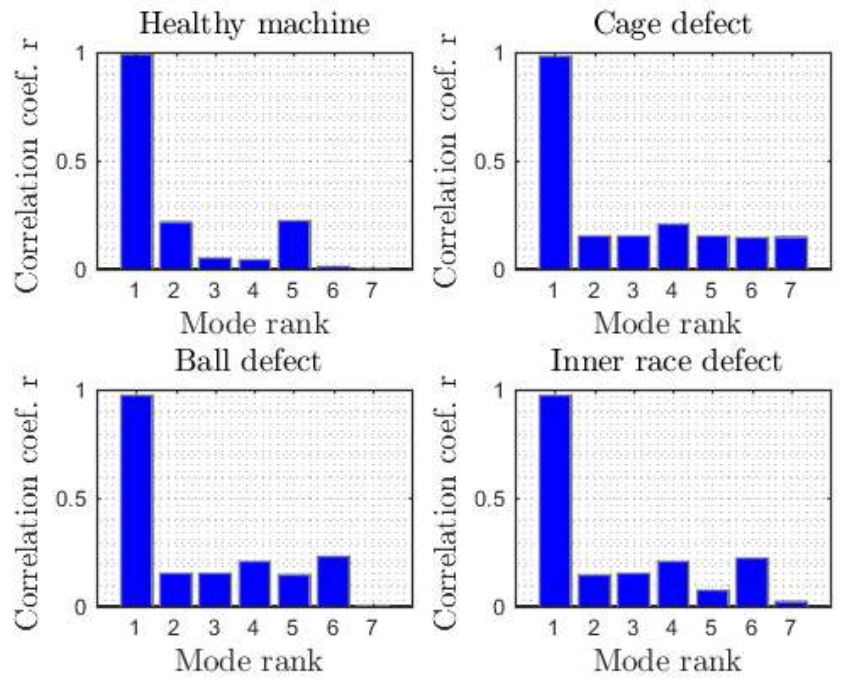

Fig. 9. Pearson correlation coefficients for VMD.

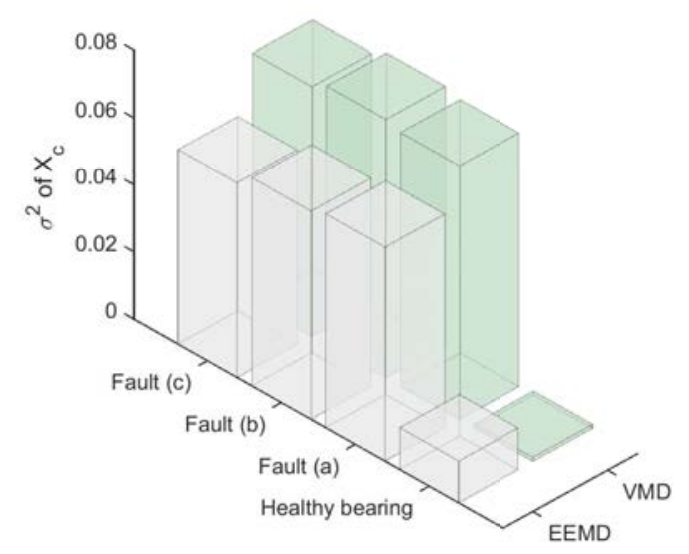

Fig. 10. Fault criterion $\sigma^{2}$ for both EEMD and VMD.

detection criterion, this criterion is performed to discriminate between healthy and faulty. The achieved experimental results have shown that the proposed method performs well for bearing faults regardless the mode rank. the performance of the proposed approach are compared to the ensemble empirical mode decomposition one in term of fault detection criterion. The achieved results clearly show that the variational mode decomposition outperforms the ensemble empirical mode decomposition.

\section{REFERENCES}

[1] A. J. M. Cardoso, Diagnosis and Fault Tolerance of Electrical Machines, Power Electronics and Drives. The Institution of Engineering and Technology, United Kingdom: IET Energy Engineering, 2018.

[2] Y. Amirat, M. Benbouzid, T. Wang, K. Bacha, and G. Feld, "Eemdbased notch filter for induction machine bearing faults detection," Applied Acoustics, vol. 133, pp. 202 - 209, 2018. [Online]. Available: http://www.sciencedirect.com/science/article/pii/S0003682X17308125 
[3] M. E. H. Benbouzid, "Bibliography on induction motors faults detection and diagnosis," IEEE Transactions on Energy Conversion, vol. 14, no. 4, pp. 1065-1074, December 1999.

[4] S. Nandi, H. A. Toliyat, and L. Xiaodong, "Condition monitoring and fault diagnosis of electrical motors - a review," IEEE Transactions on Energy Conversion, vol. 20, no. 4, pp. 719-729, December 2005.

[5] M. E. H. Benbouzid, "A review of induction motors signature analysis as a medium for faults detection," IEEE Transactions on Industrial Electronics, vol. 47, no. 5, pp. 984-993, October 2000.

[6] Y. Amirat, V. Choqueuse, and M. E. H. Benbouzid, "EEMD-based wind turbine bearing failure detection using the generator stator current homopolar component," Mechanical Systems and Signal Processing, vol. 41, no. 1, pp. 667-678, December 2013.

[7] M. Blodt, D. Bonacci, J. Regnier, M. Chabert, and J. Faucher, "Online monitoring of mechanical faults in variable-speed induction motor drives using the wigner distribution," IEEE Transactions on Industry Applications, vol. 55, no. 2, pp. 522-533, February 2008.

[8] M. Blodt, J. Regnier, and J. Faucher, "Distinguishing load torque oscillations and eccentricity faults in induction motors using stator current wigner distributions," IEEE Transactions on Industry Applications, vol. 45, no. 6, pp. 1991-2000, November 2009.

[9] J. C. Cusido, L. Romeral, J. A. Ortega, J. A. Rosero, and A. G. Espinosa, "Fault detection in induction machines using power spectral density in wavelet decomposition," IEEE Transactions on Industrial Electronics, vol. 55, no. 2, pp. 633-643, February 2008.

[10] E. Elbouchikhi, V. Choqueuse, and M. E. H. Benbouzid, "Induction machine bearing faults detection based on a multi-dimensional music algorithm and maximum likelihood estimation," ISA Transactions, vol. 63, pp. 413-424, July 2016.

[11] D. P. Mandic, N. u. Rehman, Z. Wu, and N. E. Huang, "Empirical mode decomposition-based time-frequency analysis of multivariate signals: The power of adaptive data analysis," IEEE Signal Processing Magazine, vol. 30, no. 6, pp. 74-86, November 2013.

[12] N. E. Huang, Z. Shen, S. R. Long, M. L. Wu, H. H. Shih, Q. Zheng, N. C. Yen, C. C. Tung, and H. H. Liu, "The empirical mode decomposition and hilbert spectrum for nonlinear and nonstationary time series analysis," Proceedings of Royal Society, London, vol. 454, pp. 903-995, March 1998.

[13] W. Zhou, T. Habetler, and R. G. Harley, "Bearing fault detection via stator current noise cancellation and statistical control," IEEE Transactions on Industrial Electronics, vol. 55, no. 12, pp. 4260-4269, December 2008.

[14] Z. H. Wu and N. E. Huang, "Ensemble empirical mode decomposition:

[23] F. Jiang, Z. Zhu, and W. Li, "An improved vmd with empirical mode
A noise-assisted data analysis method," Advances in Adaptive Data Analysis, vol. 1, pp. 1-41, January 2009.

[15] T. Tanaka and D. P. Mandic, "Complex empirical mode decomposition," IEEE Letters on Signal Processing, vol. 14, no. 2, pp. 101-104, February 2007.

[16] N. E. Huang and S. S. P. Shen, Hilbert-Huang Transform and Its Applications. Interdisciplinary Mathematical Sciences, 2014.

[17] D. Yu, J. Cheng, and Y. Yang, "Application of emd method and hilbert spectrum to the fault diagnosis of roller bearings," Mechanical Systems and Signal Processing., vol. 19, no. 2, pp. 259-270, March 2005.

[18] J. A. Antonino-Daviu, M. Riera-Guasp, M. Pineda-Sanchez, and R. B. Prez, "A critical comparison between DWT and Hilbert-Huang-based methods for the diagnosis of rotor bar failures in induction machines," IEEE Transactions on Industry Applications, vol. 45, no. 5, pp. 17941803, September 2009.

[19] K. Dragomiretskiy and D. Zosso, "Variational mode decomposition," IEEE Transactions on Signal Processing, vol. 62, no. 3, pp. 531-544, Feb 2014.

[20] K. He, G. K. Tso, Y. Zou, and J. Liu, "Crude oil risk forecasting: New evidence from multiscale analysis approach," Energy Economics, vol. 76, pp. $574-583,2018$.

[21] X. Chen, Y. Yang, Z. Cui, and J. Shen, "Vibration fault diagnosis of wind turbines based on variational mode decomposition and energy entropy," Energy, vol. 174, pp. 1100 - 1109, 2019. [Online]. Available: http://www.sciencedirect.com/science/article/pii/S036054421930461X

[22] Z. Wang, G. He, W. Du, J. Zhou, X. Han, J. Wang, H. He, X. Guo, J. Wang, and Y. Kou, "Crude oil risk forecasting: New evidence from multiscale analysis approach," IEEE Access, vol. 7, pp. 44871-44882, 2019.

decomposition and its application in incipient fault detection of rolling bearing," IEEE Access, vol. 6, pp. 44 483-44 493, 2018.

[24] H. Zhao and L. Li, "Fault diagnosis of wind turbine bearing based on variational mode decomposition and teager energy operator," IET Renewable Power Generation, vol. 11, no. 4, pp. 453-460, 2017.

[25] J. Harmouche, C. Delpha, and D. Diallo, "Improved fault diagnosis of ball bearings based on the global spectrum of vibration signals," IEEE Transactions on Energy Conversion, vol. 30, no. 1, pp. 376-383, March 2015.

[26] J. G. Proakis and D. G. Manolakis, Digital Signal Processing, 3rd ed. Prentice Hall, 1996.

[27] Y. Amirat, V. Choqueuse, and M. E. H. Benbouzid, "Condition monitoring of wind turbines based on amplitude demodulation," in Proceedings of 2010 IEEE Energy Conversion Congress and Exposition, 2010, pp. 2417-2421. 